\title{
How to choose and conduct a research project: some advice for young investigators
}

\author{
Como escolher e conduzir um projeto de pesquisa: \\ alguns conselhos para jovens pesquisadores
}

David A. Sullivan

Schepens Eye Research Institute, Massachusetts Eye and Ear, and Department of Ophthalmology, Harvard Medical School, Boston, MA, USA.

\section{SHOULD YOU REALLY CHOOSE TO PERFORM MEDICAL RESEARCH?}

Such a profession requires possessing a number of personal qualities, including, but not limited to, intelligence, innovative ideas, initiative, motivation, commitment, perseverance, communication skills, passion, and an ability to deal with frustration. That last quality is especially important, as frustration is frequently experienced in a medical research. In addition, to conduct medical research one needs constant external funding, which is extremely competitive and often permits only a Darwinian survival of the fittest.

\section{WHY WOULD YOU CHOOSE TO PERFORM MEDICAL RESEARCH?}

Stephen Hawking once said that his goal for conducting scientific research was simple. "It is complete understanding of the universe, why it is as it is and why it exists at all”(1). My goal for performing medical research is to make a difference in the quality of life of people.

\section{HOW SHOULD YOU CHOOSE A MEDICAL RESEARCH TOPIC?}

You should consider one that fascinates you, is important, and has broad scientific interest. For example, you might be intrigued by fungal infection of the appendix. However, Index Medicus has cited only thirty-four

Submitted for publication: November 2, 2018

Accepted for publication: November 4, 2018

Funding: No specific financial support was available for this study.

Disclosure of potential conflicts of interest: The author have any potential conflicts of interest to disclose.

Corresponding author: David Sullivan

E-mail: david_sullivan@meei.harvard.edu articles about this topic since 1960, and only one since 2016. This research area may be important, but it does not have broad scientific interest.

Another possible topic could be eye research, given that loss of vision is the greatest fear of people ${ }^{(2)}$. In particular, one focus could be the impact of sex. Sex-related differences exist in almost every cell, tissue and organ system of the body ${ }^{(3)}$, and since 1875 more than 750,000 scientific reports have been published which address the basic and/or clinical impact of sex. Moreover, the influence of sex on the eye has been known for at least 2,500 years. Thus, from the time of Hippocrates to the beginning of the 20th century, clinicians associated a variety of endocrine changes in females to alterations in the health of the eye. These included conditions such as conjunctivitis, keratitis, herpetic reactivation, corneal ulcer, blepharospasm, eyelid edema, iritis, cataract, glaucoma, amblyopia, scotoma, optic neuritis, optic nerve atrophy and blindness ${ }^{(4,5)}$. Further, in the late 1880 s, a number of European clinicians were dedicated to understanding why sex-related differences occur in the prevalence of eye diseases. Their view was that "males are by no means as prone to diseases of the eye from sexual causes as females." ${ }^{(6)}$.

Although this generalized statement may not receive much support today, it is true that many vision disorders do disproportionately affect women. These conditions include dry eye disease, hyperopia, myopia, age-related macular degeneration, cataract, refractive error, glaucoma, low vision and blindness ${ }^{(5,7)}$. I believe that recognition of these sex-related differences, and determination of their underlying basis (e.g. sex steroid action), are extremely important. I also believe that such understanding may be translated into new insights into the physiological control of ocular tissues, as well as the development of novel therapeutic strategies to treat 
diseases such as dry eye. However, it would be a challenge for a beginning investigator to choose a medical research focus in this field, given that since 1960 more than 225,000 articles have been published about sex differences, and greater than 3,600 articles explore such differences in the eye.

So then, how should you choose a medical research project as a young investigator? It would be very helpful to have a mentor, conduct a literature review and select a research niche. A mentor is "Someone who takes a special interest in helping another person develop into a successful professional”(8). For the literature review, it should be extensive, diverse, and typically start with review articles. And for a research niche, the growth potential should ideally be significant. An example is shown in figure 1 , where years ago Dr. Eduardo M. Rocha chose to study the impact of diabetes on the ocular surface, but with a particular focus on mechanism(s) underlying insulin regulation of the lacrimal gland.

\section{HOW SHOULD YOU CONDUCT A MEDICAL RESEARCH PROJECT?}

You should use the scientific method, which is an ongoing process wherein one makes observations, thinks of interesting questions, formulates hypotheses, develops testable predictions, gathers data to test predictions, refines, alters, expands or rejects hypotheses, develops general theories, and then continues to make more observations ${ }^{(9)}$. A special focus should be placed on the hypothesis, process and conclusions. For the hypothesis, one might consider the comment of Aristotle, "Intuition is the source of scientific knowledge," or the statement by Claude Levi-Strauss, "The scientific mind does not so much provide the right answers as ask the right questions." Your scientific process should feature focus, quality, controls and integrity. As concerns the conclusions, if your initial research study supports your hypothesis, repeat the experiment at least once to confirm the results.

\section{HOW SHOULD YOU DEVELOP A MEDICAL RESEARCH PROJECT?}

You should choose both short and long term experiments, which involve technical diversity and a focus on basic, clinical, epidemiological and/or translational aspects. You should also try to differentiate from your mentor's research area, always seek constructive critiques, collaborate with others, and be aware that some people, because of their immaturity, may not want you to succeed. You might also consider the quote, attributed online to the Sterling Corporation, South Africa

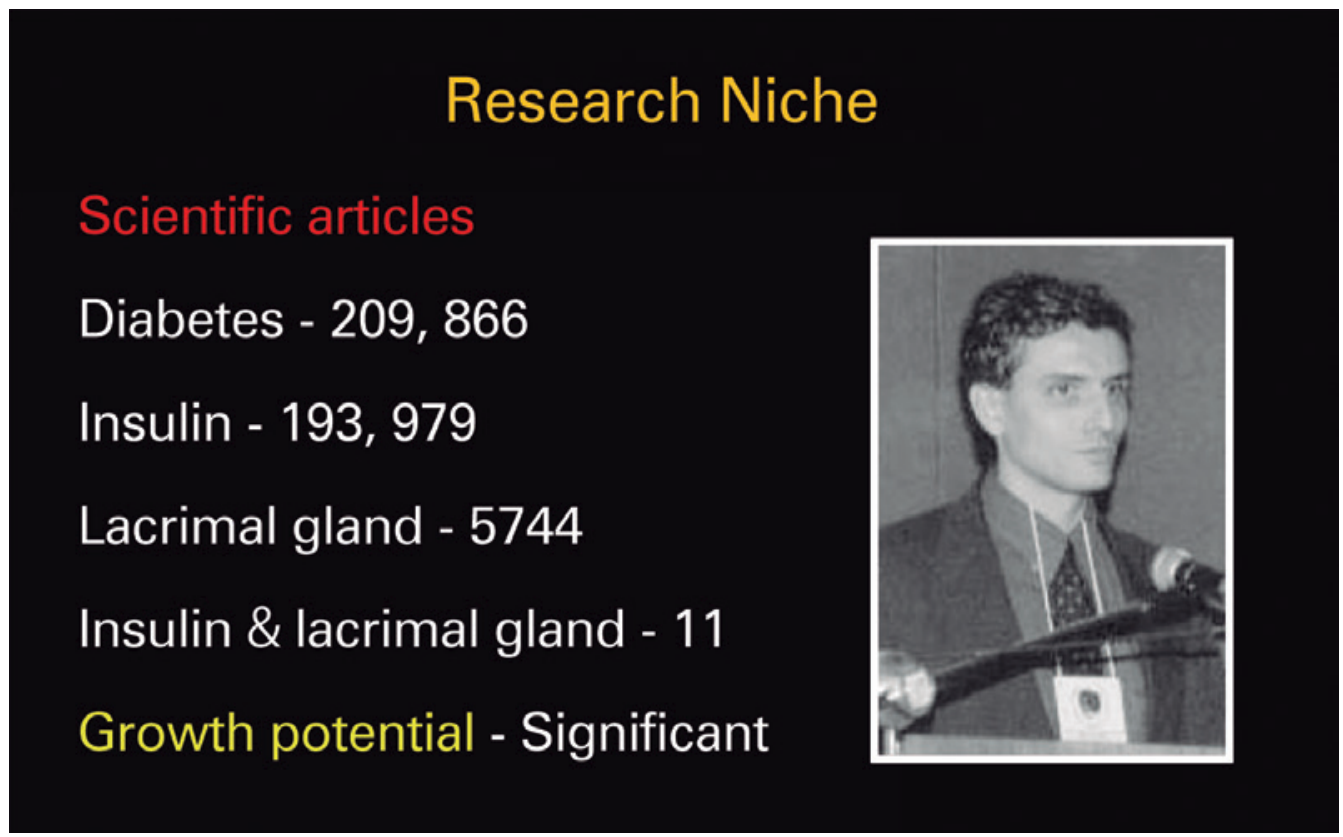

Figure 1. The growth potential of a research niche should ideally be significant, such as that chosen by one of my former postdoctoral fellows, Dr. Eduardo M. Rocha. 
that "Innovation demands creative individuals who can dream new ideas and turn them into reality."

Ultimately, you are limited only by your own imagination. You set your own medical research horizon.

\section{ACKNOWLEDGMENTS}

I would like to thank a number of Brazilians who have helped me, either directly or indirectly, to set my own global horizon. They include Monica Alves, Flavia Mendes Barsali, Leo Borges, José Álvaro P. Gomes, Denise de Freitas, Richard Yudi Hida, Helline Paz, Janethe D. O. Pena, Eduardo M. Rocha, Flavio J. Rocha, Lilia A. Rocha, Myrna Serapião dos Santos, Elcio H Sato, Ana Cristina L. M. Vendramini and Tais Hitomi Wakamatsu.

\section{REFERENCES}

1. Boslough J, Stephen Hawking's Universe. Quill, chapter 7, page 77, 1985.
2. Scott AW, Bressler NM, Ffolkes S, Wittenborn JS, Jorkasky J. Public Attitudes About Eye and Vision Health. JAMA Ophthalmol. 2016 Oct 1;134(10):1111-8.

3. Institute of Medicine (US) Committee on Understanding the Biology of Sex and Gender Differences: Exploring the Biological Contributions to Human Health: Does Sex Matter?. Washington, DC: The National Academies Press; 2001.

4. Berger E, Loewy R. In: Alcan F, editor. Ocular troubles originating from the female genital tract. Ancienne Libraire Germer Balliere et Cie, Paris. 1905.

5. Sullivan DA, Rocha EM, Aragona P, Clayton JA, Ding J, Golebiowski $B$, et al. MDP. TFOS DEWS Il Sex, Gender, and Hormones report. Ocul Surf 2017;15:284-333.

6. Kollock CW. Diseases and functional disorders of the eye, produced by normal and abnormal conditions of the sexual organs. Trans S C Med Assoc 1888:97-102.

7. Clayton JA, Davis AF. Sex/gender disparities and women's eye health. Curr Eye Res 2015;40:102-9.

8. http://ccnmtl.columbia.edu/projects/rcr/rcr_mentoring/foundation/ index.html

9. https://commons.wikimedia.org/wiki/File:The_Scientific_Method_ as_an_Ongoing_Process.svg 